\title{
The pathophysiology of osteoporotic hip fracture
}

\author{
David Metcalfe*
}

\begin{abstract}
Osteoporotic hip fractures have a profound impact on the physical health and psychosocial wellbeing of patients. In addition, osteoporosis has considerable economic implications and is projected to become an increasing burden on developed economies over the coming decades. Nevertheless, the risk factors for both osteoporosis and hip fracture are both well understood and preventable, often with only minor lifestyle changes. This narrative review explores the pathological process underlying osteoporosis and considers how each of the major risk factors contributes to the pathology of this disease. It is hoped that a greater understanding of individual risk factors will result in renewed efforts to promote increased bone density before patients present with hip fracture.
\end{abstract}

\section{INTRODUCTION}

Osteoporosis is a generalised skeletal disorder characterised by low bone mass and micro-architectural deterioration of bone which leads to fragility and risk of fracture (1). The World Health Organisation (WHO) criteria for osteoporosis are met when bone mineral density (BMD) falls 2.5 standard deviations below the mean found in young adult women (2). Reduced BMD may be caused by a range of factors such as endocrine disturbances, dietary deficiencies, or side effects of pharmacological interventions (3). One consequence of osteoporosis is hip fracture which may also be attributed to extra-skeletal factors such as frailty, failing eyesight, and a tendency to fall (4). The risk factors associated with reduced BMD are described in Table 1.

Although osteoporosis commonly affects the hip and lumbar vertebrae, it may also be found at other sites such as the radius, tibia and ribs (5). One consequence of reduced BMD is that osteoporosis is strongly associated with low trauma fracture. Indeed, up to $51 \%$ of fractures in women and $24 \%$ of those in men are attributable to osteoporosis (6). In the USA, as many as 1.5 million osteoporotic fractures are recorded annually, including 250,000 hip fractures (7). As a consequence, estimates of the economic burden of osteoporosis in the USA have climbed as high as $\$ 17$ billion per annum (8). Furthermore, in Switzerland, osteoporosis accounts for more hospital bed occupancy than myocardial infarction, stroke or breast cancer (9).

*To whom correspondence should be addressed: David Metcalfe

The Subwarden, Cryfield 3, University of Warwick Coventry, West Midlands, United Kingdom, CV4 7AL

Email: d.metcalfe@warwick.ac.uk
In addition to the economic consequences, hip fracture in particular is associated with profound disability and psychosocial sequelae. For example, 50\% of hip fracture patients lose the ability to walk without assistance and $25 \%$ require domiciliary care thereafter. Furthermore, the mortality rate over the 6 months following hip fracture may be as high as 30\% (10).

The causes of osteoporosis and hip fracture are, however, well characterised and offer multiple opportunities both for prevention and disease management. This narrative review considers the pathophysiology of osteoporosis with particular reference to fragility fractures of the hip.

\section{ANATOMY OF THE HIP}

The hip is a multiaxial ball-and-socket synovial joint in which the rounded head of the femur articulates with the concave acetabulum of the pelvis. A fibrocartilaginous lip known as the acetabular labrum increases the depth of the acetabulum and grips the femur in position (11). Both joint faces are covered with a dense lubricative layer of articular hyaline cartilage except for the fovea which holds the intracapsular ligament of the femoral head, or ligamentum teres femoris (12). The primary function of this joint is to sustain body weight in both static and dynamic postures.

Although the hip joint is only surpassed in flexibility by the glenohumeral (shoulder) joint, some range of mobility has been sacrificed in favour of further stability (13). This is probably because the weight of the upper body is entirely supported by this joint on standing (12). One consequence of this stability is that the hip joint of a healthy patient should not fracture in 


\begin{tabular}{|c|c|}
\hline General factors & $\begin{array}{l}\text { Female sex } \\
\text { Caucasian or Asian ethnicity } \\
\text { Advanced age } \\
\text { Early menopause } \\
\text { Slender habitus } \\
\text { Lack of exercise } \\
\text { Smoking } \\
\text { Family history } \\
\text { Excess alcohol } \\
\text { Poor nutrition (low calcium or high protein) }\end{array}$ \\
\hline Drug products & $\begin{array}{l}\text { Corticosteroids } \\
\text { Heparin } \\
\text { Cyclosporin } \\
\text { Cytotoxic drugs }\end{array}$ \\
\hline \multicolumn{2}{|l|}{ Diseases } \\
\hline - Endocrine disease & $\begin{array}{l}\text { Cushing's syndrome } \\
\text { Hyperparathyroidism } \\
\text { Hypogonadism } \\
\text { Acromegaly } \\
\text { Type I diabetes mellitus }\end{array}$ \\
\hline - Joint disease & Rheumatoid arthritis \\
\hline - Other diseases & $\begin{array}{l}\text { Chronic renal failure } \\
\text { Chronic liver disease } \\
\text { Mastocytosis } \\
\text { Anorexia nervosa } \\
\text { Inflammatory bowel disease } \\
\text { Coeliac disease }\end{array}$ \\
\hline
\end{tabular}

Table 1: Risk factors predisposing to low BMD (20).

the absence of high energy trauma. Indeed, the femoral head is classically fractured only in high impact road traffic accidents in which the dash board strikes the knee to rupture the joint capsule (14).

However, the femoral head is supported by a relatively thin structure known as the femoral neck which is more prone to fracture than the joint itself is to dislocation (13). The femoral neck is particularly vulnerable in patients suffering from bone disorders such as Paget's disease, osteomalacia, osteopetrosis, osteogenesis imperfecta and metabolic bone disease. Femoral neck fractures are also frequently associated with primary tumours of the bone, cancer metastases and infection of the bone (15). However, the majority of patients presenting with femoral neck fractures are those with osteoporosis (16). Although osteoporosis may be caused by multiple factors, all of these are thought to act by subverting the normal physiology of healthy bone.

\section{PHYSIOLOGY OF BONE}

Mammalian bones may be classified as long, short, flat, irregular or sesamoid. The long bones, which include the femurs, are a major component of the human skeleton and fulfil a number of different functions. As well as protecting soft tissues and determining posture, long bones also provide a site for haematopoiesis. Furthermore, they are important sites of mineral storage, particularly of calcium and phosphate (17). The multiple functions of bone require a dynamic structure to cope with mineral storage and adaptation to environmental stress. For these reasons, osseous tissue is continually broken down and redeposited in a process known as 'remodelling'.

\section{Bone remodelling}

In healthy adult bone, matrix exists in a dynamic equilibrium of deposition by osteoblasts and resorption by osteoclasts. The latter typically aggregate together and eliminate bone over a period of $\sim 3$ weeks, leaving a tunnel of between $0.2 \mathrm{~mm}$ and $1 \mathrm{~mm}$. Osteoblasts then act to deposit new matrix and these cells may be found acting on $4 \%$ of the surface of adult human bone at any time (18). New bone is deposited in concentric circles known as lamellae and, in this way, up to $10 \%$ of bone is re-deposited in the adult skeleton each year (19). The purposes of continual bone remodelling are twofold:

1. Adjustment of bone shape and thickness in response to environmental and musculoskeletal stresses.

2. Replenishment of old bone which is weaker than newly deposited matrix (19).

\section{AETIOLOGY OF OSTEOPOROSIS}

A number of risk factors for reduced BMD exert their effect through subversion of the remodelling process. Indeed, osteoporosis may be seen simply as a failure of bone deposition to match the rate of resorption (19). Many of these risk factors were summarised earlier in Table 1. Although a number affect patients in adulthood, many other risk factors exert their influence during adolescence or earlier in the lifespan when bone deposition initially takes place (19).

\section{Alcohol and tobacco consumption}

Many studies have suggested an association between excess alcohol consumption and fragility fractures. One large cohort study has, for example, shown that heavy alcohol consumption ( $>207 \mathrm{ml}$ per week) accompanies an increased risk of fracture in men $(R R=1.26)$ and women $(R R=1.54)(21)$. This relationship is not simply a result of falls under the influence of alcohol as histological changes have also been noted in the bone structure of alcohol abusers (22). However, these may be partially explained by confounding factors associated with alcoholism such as liver damage, hypogonadism and nutritional deficiencies. Nevertheless, alcohol is known to increase parathyroid hormone (PTH) and to reduce concentrations of vitamin $\mathrm{D}$ metabolites required for efficient calcium absorption (23). Furthermore, alcohol suppresses bone mineralization by osteoblasts. The consequences of 
these effects are calcium excretion in the urine (hypercalciuria), lowered serum calcium (hypocalcaemia) and reduced BMD (23). Despite these risks, a mounting body of evidence suggests that moderate alcohol intake may increase BMD, possibly by increasing oestrogen titres (22).

Individuals who smoke tobacco are at increased risk of developing osteoporosis, even when alcohol is eliminated as a confounding factor. Although the precise mechanism is not understood, there remains a clear dose-dependent relationship between smoking and reduced BMD (24).

\section{High salt diet}

Additional dietary risk factors include high salt and high protein diets. Although excessive salt consumption $(>9 \mathrm{~g} /$ day) is not itself a cause of osteoporosis (25), it is known to reduce BMD by increasing renal calcium excretion (26). Indeed, every $100 \mathrm{mmol}$ of ingested sodium is thought to deplete the body of around $1 \mathrm{mmol}$ of calcium (27). Protein also increases the level of renal calcium excretion. One longitudinal study has, for example, found that high dietary protein causes hypercalciuria and reduced BMD in the elderly (28). Indeed, increasing dietary protein ingestion from $40 \mathrm{~g}$ to $80 \mathrm{~g}$ leads to the excretion of an additional $1 \mathrm{mmol}$ calcium each day (27). Low protein diets have, however, also been associated with fracture, although this apparent relationship may be explained by confounding factors such as malnutrition and slender habitus (28).

\section{Dietary deficiencies and anorexia nervosa}

Poor nutrition is also strongly associated with reduced BMD. According to one meta-analysis of 20 studies, the increased calcium requirement and reduced absorption at menopause may be negated by calcium supplementation (27). Other nutritional factors also affect calcium homeostasis. For example, vitamin D is required for efficient absorption of calcium and one meta-analysis has shown that calcium and vitamin D are more effective than calcium alone in elevating BMD (29). Vitamin D deficiencies, then, are associated with calcium malabsorption, reduced BMD and increased risk of hip fracture (27). As sunlight is a necessary component of vitamin D synthesis, populations exposed less frequently to the sun are at increased risk. Such populations include women dressed according to Shariah law and the homebound elderly. One study has shown that $38 \%$ of nursing home residents in the USA had serum levels of 25-hydroxyvitamin D (25-OHD) below $25 \mathrm{nM}$, compared with a normal range of 25 $137 \mathrm{nM}$ (30). Similarly, the prevalence of vitamin D deficiency and high bone turnover in a cohort of
Muslim women living in Australia was found to be $68 \%$ and $38.6 \%$ respectively (31).

Vitamin $\mathrm{K}$, obtained primarily from leafy green vegetables, is another agent that protects bone matrix. It fulfils this function primarily through facilitating the carboxylation of glutamyl residues on bone proteins such as osteocalcin. One prospective study of 72,237 women, for example, found that those with a low vitamin $\mathrm{K}$ intake were significantly more likely to suffer a low trauma hip fracture (32).

These dietary deficiencies, as well as hormonal changes secondary to cachexia, are responsible for the reduced BMD observed in patients with anorexia nervosa. Nutritional rehabilitation can increase the BMD of women with anorexia nervosa beyond that achieved with administration of oestrogen alone (33). Slender habitus is, however, an independent risk factor for osteoporosis with both total fat mass and total lean mass exerting a protective effect on bone in postmenopausal women (34).

\section{Glucocorticoid administration}

Glucocorticoids are a class of steroid hormones that bind the intracellular cortisol receptor. They are primarily used for their anti-inflammatory properties in respiratory, musculoskeletal and cutaneous diseases. Indeed, around $0.9 \%$ of people on the United Kingdom General Practice Research Database are prescribed glucocorticoids at any one time (35). Glucocorticoids are, however, associated with greatly reduced BMD. They are the most frequent cause of secondary osteoporosis and as many as $50 \%$ of patients receiving long-term glucocorticoid therapy sustain a fragility fracture(36). In particular, the relative risk of hip fracture in patients receiving a daily glucocorticoid dose of $\geq 30 \mathrm{mg}$ is 3.13 (95\% CI $=1.49-6.59)$ (37).

These drugs exert their osteoporotic effects through a number of mechanisms. For example, they impair the replication and differentiation of osteoblasts, as well as induce apoptosis in mature osteoblasts (36). Glucocorticoids also downregulate genes encoding matrix proteins such as collagen and osteocalcin(38). Finally, glucocorticoids are associated with reduced intestinal calcium absorption as a result of downregulating the gene encoding TRPV6, a Ca2+ channel normally expressed in duodenal epithelium (39). Although vitamin D supplementation given alongside glucocorticoids can negate the damage to bone, awareness of glucocorticoid-induced osteoporosis remains low among primary and secondary care physicians (40).

\section{Female sex}

Women account for over $80 \%$ of osteoporosis 
diagnoses (41). Female sex is a risk factor for low BMD both because of the reduced size and cortical thickness characteristic of female bones and the decline in oestrogen titres at menopause (42). Oestrogen has a protective effect on bone, primarily by blocking osteoclast activity. It achieves this through the inhibition of a number of cytokines, including IL-1 and TNF, which otherwise activate mature osteoclasts (43). The bone-sparing properties of oestrogen explain why early menopause predisposes to low BMD and underlies the rationale for using hormone replacement therapy (HRT) to avert osteoporosis. Indeed, postmenopausal oestrogen deficiency is the most significant non-genetic factor in the aetiology of osteoporosis (25).

Pregnancy has, however, also been associated with osteoporosis, particularly with vertebral fragility fractures in the third trimester (44). Nevertheless, longterm studies of postpartum women using dual-energy X-ray absorptiometry (DEXA) have found that reduced BMD during pregnancy and lactation is usually only a temporary phenomenon (45). Although cases of osteoporotic hip fracture have been reported during pregnancy(46), the extent of this relationship has yet to be determined.

Although predominantly a disease of older women, men do suffer from osteoporosis. In Croatia, as many as $5.8 \%$ of men over 50 qualify as osteoporotic on analysis of the calcaneus using a quantitative ultrasound (QUS) index (47). Men in the United States account for up to $30 \%$ of hip fracture diagnoses (48). Interestingly, male hip fracture patients experience larger rates of morbidity and mortality than their female counterparts (49). Osteoporosis risk factors for men are specifically glucocorticoid or anticonvulsant therapy, testosterone or oestrogen deficiency, smoking, and alcohol consumption (50). In particular, out of the 6.5 million American men projected to suffer from symptomatic androgen deficiency in $2025,650,000$ are expected to suffer a fragility fracture as a consequence (51). Furthermore, many men suffer from idiopathic osteoporosis which can occur at any age (42).

\section{Advanced age}

Bone mineral deposition accelerates during childhood and adolescence but trabecular bone loss begins early in midlife and accelerates with increasing age (42). Although menopause accounts for much of the association between age and osteoporosis, bone ageing occurs even before the menopause in many women (52). The actual aetiology of age-related bone loss is unknown, although it is understood to involve an imbalance in bone remodelling. Possible explanations include reduced osteoblast lifespan, increased osteoclast lifespan, abnormal osteocyte signalling or a physiological response to inactivity in old age (53). The efficiency of calcium absorption in the duodenum is also known to decline with age (19).

\section{EXTRA-SKELETAL RISK FACTORS FOR HIP FRACTURE}

Although reduced BMD in osteoporosis elevates fracture risk, fracture itself may also be attributed to falling, often from standing height. Table 2 summarises the most significant extra-skeletal risk factors which may lead to falling and subsequent fracture. Falls prevention services have now been implemented by a number of countries and have had some success in reducing the incidence of hip fractures among elderly populations (54).

\section{HEALTH PROMOTION}

Health promotion strategies primarily aim to eliminate modifiable risk factors. As osteoporosis screening is not commonplace, these strategies are often targeted at populations considered to be 'at risk'. Weight bearing exercise is, for example, recommended for elderly community-dwelling people (57). Nonpharmacological interventions include exercise, redress of dietary deficiencies and falls prevention. These health promotion strategies are also an extremely important aspect of fragility fracture management.

Non-pharmacological interventions may be used both as preventative measures and as management strategies following hip fracture. Exercise and dietary intake are important considerations throughout the lifespan as skeletal strength in old age is largely determined by mineral deposition in childhood and adolescence (19).

\section{Exercise}

A number of systematic reviews have concluded that weight bearing exercise can increase BMD in both healthy and osteoporotic women (58). In light of this evidence, resistance and strength training are now

\begin{tabular}{|l|l|}
\hline Intrinsic Factors & Balance, gait or mobility problems \\
& Medications \\
& (e.g. sedatives, anti-hypertensive drugs) \\
& Visual impairment \\
& Impaired cognition \\
& Postural hypotension \\
& Alcohol \\
\hline Environmental factors & $\begin{array}{l}\text { Poor lighting } \\
\text { Steep stairs } \\
\text { Carpets or rugs } \\
\text { Slippery floors } \\
\text { Badly fitting footwear } \\
\text { Inaccessible cupboards or windows }\end{array}$ \\
\hline
\end{tabular}

Table 2: Extra-skeletal risk factors for hip fracture $(55,56)$. 
commonly found in rehabilitation physiotherapy programmes for osteoporotic fracture patients (59). As exercise should be directed specifically at the site of bone ageing, hip fracture patients are often encouraged to walk with the aid of a stick or frame (59).

Although BMD gains as a result of exercise are reversible, strengthened muscles provide additional support to vulnerable regions such as the femoral neck (19). Furthermore, moderate exercise during childhood is associated with a $10 \%$ increase in BMD at the hip which may reduce the risk of fracture in old age (60).

\section{Calcium and vitamin D}

Dietary calcium is as effective as pharmacological treatment in maintaining bone health (61). Indeed, one meta-analysis has found that $1000 \mathrm{mg}$ dietary calcium a day can reduce fracture risk by $24 \%$ (62). Furthermore, dietary calcium is associated with higher oestrogen titres and BMD than is calcium supplementation (63). Supplementation is, however, a useful and economical device for patients unwilling or unable to ingest adequate quantities of dietary calcium. Nevertheless, excess calcium $(>1500 \mathrm{mg} /$ day $)$ has been associated with advanced prostate cancer in men and kidney stones in those with renal insufficiency (64).

Elderly patients may also be administered 400-800 IU vitamin $\mathrm{D}$ daily, in addition to the $700-800 \mathrm{mg}$ calcium that is currently recommended (65). Vitamin D and calcium in combination are more effective than calcium supplementation alone as the former is a vital component of calcium absorption (29). Furthermore, vitamin $\mathrm{D}$ supplementation is known to increase both parathyroid hormone $(\mathrm{PTH})$ concentrations and $\mathrm{BMD}$, particularly at the femoral neck (19).

\section{Falls prevention}

Although there is little to gain from providing falls advice to healthy older people, those who are frail or osteoporotic are known to benefit from referral to a falls prevention service (66).

The most successful falls services are Multifactorial Fall Prevention Programmes (MFPPs). Indeed, there is little evidence in favour of education or environment modification programmes in isolation (67). MFPP teams typically include a consultant geriatrician in addition to allied health care workers such as physiotherapists, nurses, occupational therapists, chiropodists, pharmacists and social workers (64). The programme itself includes a strong element of assessment with each patient treated as an individual and a falls prevention strategy targeted at each of their particular risk factors. There are, however, a number of problems related to the referral of patients to falls services. For example, a high number of referred patients are false positives and may never have been at increased risk of falling (4) A number of systematic reviews have, however, shown that falls interventions can reduce the rate of fracture in the elderly (67).

In addition to falls prevention, patients may use mechanical protection such as hip protectors. Although some trials have shown these to be ineffective, others with longer follow-up times have implied a reduced hip fracture risk (68). One systematic review of seven randomised controlled trials (RCTs) found that hip protectors reduce hip fracture risk by up to $66 \%$ (69). Hip protectors are, however, affected by poor compliance, with less than a third of patients using them regularly (70). It is furthermore unclear whether hip protectors are cost-effective (71). For this reason, their use is limited.

\section{CONCLUSION}

Although a number of different factors can contribute to osteoporosis, most of these reduce BMD by interfering with the bone remodelling process. Furthermore, many of the risk factors for osteoporosis and hip fracture identified in this review are preventable, particularly if challenged early in the lifespan. For example, exercise and dietary intake are important considerations at an early age, as skeletal strength in old age is largely determined by mineral deposition in childhood and adolescence (19). A greater understanding of the pathophysiology of osteoporosis is likely to inform health promotion strategies aimed both at primary and secondary prevention of this disease. Furthermore, awareness of factors predisposing to falls may help reduce the incidence of hip fracture among those elderly persons already suffering from osteoporosis.

\section{REFERENCES}

1. Rodan GA. Good hope for making osteoporosis a disease of the past. Osteoporos Int. 4:S5-S6; 1994

2. World Health Organization. Assessment of fracture risk and its application to screening for post-menopausal osteoporosis. Report of a WHO Study Group 2004.

3. Shipley M, Black CM, Denton CP, Compston J, O'Gradaigh D. Rheumatology and bone disease. In: Kumar P, Clark M, editors. Clinical Medicine. Philadelphia: Elsevier Saunders, 2005.

4. Chartered Society of Physiotherapy. Effectiveness of falls prevention and rehabilitation strategies in older people: implications for physiotherapy. London: CSP 2001.

5. Cauley JA. Osteoporosis in men: prevalence and investigation. Clin Cornerstone. 8:S20-S25; 2006.

6. Lippuner K, Golder M, Greiner R. Epidemiology and direct medical costs of osteoporotic fractures in men and women in Switzerland. Osteoporos Int. 16:S8-S17; 2005.

7. Riggs BL, Melton LJ. The worldwide problem of osteoporosis: insights afforded by epidemiology. Bone 17:505S-511S; 1995.

8. Keen, R. W. Burden of osteoporosis and fractures. Curr Osteoporos Res. 1:66-70; 2003.

9. Lippuner K, von Overbeck J, Perrelet R, Bosshard H, Jaeger P. 
Incidence and direct medical costs of hospitalizations due to osteoporotic fractures in Switzerland. Osteoporos Int. 7:414$425 ; 1997$.

10. Goldacre MJ, Roberts SE, Yeates D. Mortality after admission to hospital with fractured neck of femur: database study. BMJ 325:868-869; 2002.

11. Snell RS. Clinical Anatomy. 7th ed. New York: Lippincott Williams \& Wilkins, 2003:636-644.

12. Moore KL, Dalley AF. Clinically Orientated Anatomy. 5th ed. New York: Lippincott Williams \& Wilkins, 2006.

13. Reece VAC. Fractured neck of femur: a guide for immediatecare nurses in the Accident \& Emergency department. South Tyneside Health care NHS Trust 2002.

14. Jessberger S, Blattert TR, Wagner R, Weckbach A. Reducing approach-associated morbidity in fracture dislocation of the femoral head - a longitudinal study (1982-2000). Zentralbl Chir 127:485-489; 2002

15. Golzman D. Discoveries, drugs and skeletal disorders. Nature 1:784-796; 2002

16. Hordon LD, Peacock M. Osteomalacia and osteoporosis in femoral neck fracture. Bone Miner. 11:247-259; 1990.

17. Dempster DW. Osteoporosis in men. In: Favus MJ, ed. Primer on the Metabolic Bone Diseases and Disorders of Mineral Metabolism. Washington DC: The American Society for Bone and Mineral Research, 2006.

18. Guyton AC, Hall JE eds. Medical Physiology, 10th edition. WB Saunders Company: Philadelphia, 2000.

19. World Health Organisation. Prevention and Management of Osteoporosis. WHO Technical Report Series 2003.

20. Kanis JA, Johnell O, Gullberg B et al. Risk factors for hip fracture in men from Southern Europe: the MEDOS study. Osteoporos Int. 9:45-54; 1999.

21. Felson TF, Douglas PK, Jennifer JA, Kannel WB. Alcohol consumption and hip fractures: the Framingham study. Am J Epidemiol. 128:1102-1110; 1998.

22. Turner RT, Sibonga JD. Effects of alcohol use and estrogen on bone. National Institute on Alcohol Abuse and Alcoholism 2002

23. Laitinen K, Valimaki M. Alcohol and bone. Calcif Tissue Int. 49:S70-S73; 1991.

24. Wong PK, Christie JJ, Wark JD. The effects of smoking on bone health. Clin Sci (Lond) 113:233-241; 2007.

25. Cohen AJ, Roe FJ. Review of risk factors for osteoporosis with particular reference to a possible aetiological role of dietary salt. Food Chem Toxicol. 38:237-253; 2000.

26. Massey LK. Effect of dietary salt intake on circadian calcium metabolism, bone turnover, and calcium oxalate kidney stone risk in postmenopausal women. Nutrition Research 25:891-903; 2005.

27. Nordin BEC, Need AG, Steurer T, Morris HA, Chatterton BA, Horowitz M. Nutrition, osteoporosis and aging. Ann N Y Acad Sci. 854:336-351; 1998.

28. Hannan MT, Tucker KL, Dawson-Hughes B, Cupples LA, Felson DT, Kiel DP. Effect of dietary protein on bone loss in elderly men and women: the Framingham osteoporosis study. J Bone Min Res. 15:2504-2512; 2000.

29. Amin S, LaValley MP, Simms RW, Felson DT. The role of vitamin D in corticosteroid-induced osteoporosis: a metaanalytic approach. Arthritis Rheum 42:1740-1751; 1999.

30. Gloth FM, Smith CE, Hollis BW, Tobin JD. Functional improvement with vitamin D replenishment in a cohort of frail, vitamin D-deficient older people. J Am Geriatr Soc. 43:1269$1271 ; 1995$.

31. Diamond TH, Levy S, Smith A, Day P. High bone turnover in Muslim women with vitamin D deficiency. Med J Aust. 177:139-141; 2002.

32. Feskanich D, Weber P, Willett WC, Rockett H, Booth SL,
Colditz GA. Vitamin K intake and hip fractures in women: a prospective study. Am J Clin Nutr 69:74-79; 1999.

33. Dominguez J, Goodman L, Gupta S, Mayer L, Etu SF, Walsh BT, Wang J, Pierson R, Warren MP. Treatment of anorexia nervosa is associated with increases in bone mineral density, and recovery is a biphasic process involving both nutrition and return of menses. Am J Clin Nutr 86:92-99; 2007.

34. Gnudi S, Sitta E, Fiuimi N. Relationship between body composition and bone mineral density in women with and without osteoporosis: relative contribution of lean and fat mass. J Bone Miner Metab. 25:329-332; 2007.

35. van Staa TP, Leufkens HGM, Abenhaim L, Begaud B, Zhang B. Use of oral corticosteroids in the United Kingdom. Q J Med. 93:105-111; 2000

36. Canalis E, Mazziotti G, Giustina A, Bilezikian JP. Glucocorticoid-induced osteoporosis: pathophysiology and therapy. Osteoporos Int. In Press.

37. de Vries F, Bracke M, Leufkens HG, Lammers JW, Cooper C, van Staa TP. Fracture risk with intermittent high-dose oral glucocorticoid therapy. Arthritis Rheum. 56:208-214; 2007.

38. Lane NE. An update on glucocorticoid-induced osteoporosis. Curr Opin Rheumatol. 27:235-253; 2001.

39. Huybers S, Naber Th, Bindels RJ, Hoenderop JG. Prednisoloneinduced $\mathrm{Ca} 2+$ malabsorption is caused by diminished expression of the epithelial Ca2+ channel TRPV6. Am J Physiol Gastrointest Liver Physiol 292:92-97; 2007.

40. Compston JE. Emerging consensus on prevention and treatment of glucocorticoid-induced osteoporosis. Curr Rheumatol Rep. 9:78-84; 2007.

41. National Osteoporosis Foundation. Physician's guide to prevention and treatment of osteoporosis. Washington DC: National Osteoporosis Foundation, 2003.

42. Orwoll ES. Osteoporosis in men. In: Favus MJ, ed. Primer on the Metabolic Bone Diseases and Disorders of Mineral Metabolism. Washington DC: The American Society for Bone and Mineral Research, 2006.

43. Pacifici R. Estrogen, cytokines, and pathogenesis of postmenopausal osteoporosis. J Bone Miner Res. 11:1043-1051; 1996.

44. Dunne F, Walters B, Marshall T, Heath DA. Pregnancy associated osteoporosis. Clin Endocrinol (Oxf) 39:487-490; 1993.

45. Karlsson C, Obrant KJ, Karlsson M. Pregnacy and lactation confer reversible bone loss in humans. Osteoporos Int. 12:828$834 ; 2001$.

46. Thomas E, Cox C, Murphy D, Beddard K. Hip fracture during labour due to transient osteoporosis of the hip in pregnancy. J Obstet Gynaecol. 20:197-198; 2000.

47. Kastelan D, Kralijevic I, Kujundzic-Tiljak M, et al. Osteoporosis prevalence in Croatian males - the results of calcaneus ultrasound. Lijec Vjesn 129:123-129; 2007.

48. Cooper C, Campion G, Melton LJ. Hip fractures in the elderly: a world-wide projection. Osteoporos Int. 2:285-289; 1992.

49. Amin S, Felson DT. Osteoporosis in men. Rheum Dis Clin North Am 27:19-47; 2001.

50. Campion JM, Maricic MJ. Osteoporosis in men. Am Fam Physician 67:1521-1526; 2003.

51. Araujo AB, Esche GR, Kupelian V, et al. Prevalence of symptomatic androgen deficiency in men. J Clin Endocrinol Metab. In Press.

52. Riggs BL, Wahner HW, Melton LJ, et al. Rate of bone loss in the axial and appendicular skeleton of women: evidence of substantial bone loss prior to menopause. J Clin Invest 77:1847$1891 ; 1986$.

53. Seeman E. Pathogenesis of bone fragility in women and men. Lancet 359:1841-1850; 2002. 
54. Gillespie LD, Gillespie WJ, Cumming R, Lamb SE, Rowe BH. Interventions for preventing falls in the elderly. In: Cochrane Library. Issue 1. Oxford: Update Software, 2003.

55. Chartered Society of Physiotherapy. Effectiveness of falls prevention and rehabilitation strategies in older people: implications for physiotherapy. London: CSP, 2001.

56. Department of Health. National service framework for older people. London: DoH, 2001.

57. American Geriatrics Society, British Geriatrics Society and American Academy of Orthopedic Surgeons. Panel on Falls Prevention. Guidelines for the prevention of falls in older persons. J Am Geriatr Soc. 2001 49:664-672.

58. Ernst E. Exercise for female osteoporosis: a systematic review of randomised clinical trials. Sports Medicine 1998 25:359-368.

59. Scottish Intercollegiate Guidelines Network. Management of osteoporosis: a national clinical guideline. Edinburgh: Royal College of Physicians, 2003:15-29.

60. Morris FL, Naughton GA, Gibbs JL, Carlson JS, Wark JD. Prospective ten-month exercise intervention in premenarcheal girls: positive effects on bone and lean mass. J Bone Miner Res. 1997 12:1453-1462.

61. Weinsier RL, Krumdieck CL. Dairy foods and bone health: examination of the evidence. Am J Clin Nutr. 2000 72:681-689.

62. Cumming RG, Nevitt MC. Calcium for prevention of osteoporotic fractures in postmenopausal women. J Bone Miner Res. 1997 12:1321-1329.

63. Napoli N, Thompson J, Civitelli R, Armamento-Villareal RC. Effects of dietary calcium compared with calcium supplements on estrogen metabolism and bone mineral density. Am J Clin Nutr. 2007 85:1428-1433.

64. Straub DA. Calcium supplementation in clinical practice: a review of forms, doses, and indications. Nutr Clin Pract. 2007 22:286-296.

65. Gennari C. Calcium and vitamin D nutrition and bone disease of the elderly. Public Health Nutr. 2001 4:547-559.

66. Gillespie LD, Gillespie WJ, Cumming R, Lamb SE, Rowe BH. Interventions for preventing falls in the elderly. In: Cochrane Library. Issue 1. Oxford: Update Software, 2003.

67. Chang JT, Morton SC, Rubenstein LZ, et al. Interventions for the prevention of falls in older adults: systematic review and meta-analysis of randomised clinical trials. BMJ 2004 328:680684.

68. Cowling PD. Hip protectors and their role in hip fracture prevention: a review. McGill Journal of Medicine 2004 8:58-65.

69. Parker M. Diagnosis and immediate care of fractured neck of femur. Hosp Med. 2001 63:42-43.

70. Birks YF, Porthouse J, Addie C, et al. Randomized controlled trial of hip protectors among women living in the community. Osteoporos Int. 2004 15:701-706.

71. van Schoor NM, de Bruyne MC, van der Roer N, et al. Costeffectiveness of hip protectors in frail institutionalzed elderly. Osteoporos Int. 2004 15:964-969.

David Metcalfe (MBChB, 2010) is an undergraduate at the Warwick Medical School in the United Kingdom. He received a first class honors degree in Biological Sciences with Molecular Genetics from the University of Warwick in 2006. His research interests include molecular medicine, orthopedic pathology, and public health. 